\title{
IMPACTO DO USO DE ADITIVOS NA CONSERVAÇÃO E NA EFICIÊNCIA DA COMBUSTÃO DO DIESEL
}

\author{
Jair Duarte $^{1}$, Ezequiel Orlandi ${ }^{2}$ e Gilles Laurent Grimberg ${ }^{1}$ \\ ${ }^{1}$ Actioil do Brasil \\ ${ }^{2}$ Institutos Lactec
}

E-mails: jair@actioil.com, ezequielorlandi@hotmail.com, gilleslaurent@actioil.com

\section{RESUMO}

Com a mudança na legislação e a necessidade de crescimento da nossa matriz energética, é importante fazer algumas mudanças no setor da energia, bem como nas composições dos combustíveis, principalmente entre os derivados de petróleo. Pensando sobre o aquecimento global e a poluição em geral, é imprescindível fazer uma avaliação crítica no desenvolvimento de novos combustíveis e também ao ajustar aqueles que já estão em uso. Quanto ao uso do diesel, com o corte do enxofre, a tendência é a redução das emissões de enxofre para a atmosfera. No entanto, a extração desses elementos causa danos ao combustível, como redução da sua capacidade de lubrificação e sua ação no combate à proliferação de microrganismo. Para corrigir o problema de lubrificação e pensar sobre a redução do consumo de petróleo, começamos a adicionar biodiesel ao diesel. Biodiesel é altamente higroscópico, o que traz alguns problemas para o motor como a diminuição na potência, obstrução do sistema de injeção, corrosão e até mesmo a proliferação bacteriana, causando depósitos, conhecidos como borra. O uso de aditivos multifuncionais, como é mostrado ao longo deste trabalho, fornece uma maneira eficiente e ambientalmente amigável de superar esses problemas. $\mathrm{O}$ trabalho se caracteriza por um estudo de caso da aplicação do aditivo A550 da Actioil no diesel utilizado na usina termoelétrica de Santana, pertencente à Eletronorte, no estado do Amapá. O diesel aditivado foi adquirido da Petrobras Distribuidora.

\section{INTRODUÇÃO}

Embora não sendo a principal forma de geração de energia elétrica do país, correspondendo por aproximadamente $2,6 \%$ da matriz energética do país (ANEEL), as termoelétricas merecem especial atenção em seu processo por conta da quantidade de combustíveis fósseis que consomem.

A queima de combustíveis fósseis lança grande quantidade de poluentes na atmosfera. Os gases contendo enxofre e nitrogênio $\left(\mathrm{SO}_{\mathrm{x}}\right.$ e $\left.\mathrm{NO}_{\mathrm{x}}\right)$ reagem com a água causando a acidificação dos solos e corpos d'água. Tais gases quando inalados também causam diversos efeitos adversos à saúde, principalmente de populações mais fragilizadas, como idosos e crianças. O dióxido de carbono tem efeitos adversos no clima e é atualmente foco de diversos estudos quanto à sua real 
contribuição para o aquecimento global (Nidal \& Abu-Hamadeh, 2003; Lapuerta, Armas, \& Rodríguez-fernández, 2008).

Além dos compostos colocados acima, outras substâncias são liberadas quando se há a queima incompleta ou ineficiente do combustível. Tal é o caso do monóxido de carbono, gás extremamente nocivo devido à sua alta afinidade com a hemoglobina sanguínea. Também podese citar os diversos compostos orgânicos formados que com sua variedade de grupos funcionais impactam diretamente a saúde dos seres vivos. Tais compostos são agrupados sob o nome de compostos orgânicos voláteis (VOCs) (Chigier, 1986).

Dentre as substâncias potencialmente poluidoras geradas na queima dos combustíveis fósseis, há ainda a preocupação com a liberação na atmosfera de compostos particulados. Tais compostos formadores da fuligem, observada em gases de combustão, são frutos de combustão desregulada, falta de especificação ou contaminação do combustível (Lewtas, 2007).

Para cada um dos poluentes colocados há limites de concentração, nos gases de combustão, aceitos por lei. Porém, com o avanço científico denunciando cada vez mais os malefícios da poluição à saúde e ao meio-ambiente, observa-se um acirramento dos limites. No setor industrial, por questões de volume de emissões, essas restrições devem ser prontamente atendidas. Assim, as indústrias cada vez mais focam sua atenção em como produzir mais, de forma competitiva e ainda assim atender às legislações vigentes.

Quando se trata das usinas geradoras de energia, principalmente as termoelétricas, um dos principais pontos a serem observados é o correto e eficiente uso de sua principal matéria prima: o óleo diesel.

O óleo diesel é um combustível obtido na destilação do petróleo e se caracteriza principalmente por ser uma fração mais pesada do que a gasolina, sendo constituído por cadeias grandes cadeias carbônicas, ramificadas ou não. Por ser uma fração mais pesada, também traz maiores quantidades de nitrogênio, oxigênio e enxofre, os quais influenciarão diretamente na emissão de gases poluidores (Speight, 2006; Fahim, Al-Sahhaf, \& Elkilani, 2010).

O governo brasileiro adotou uma política de mistura do biodiesel ao diesel, diminuindo assim o consumo de combustíveis fósseis, ao mesmo tempo que diminuiu a quantidade aceita de enxofre no diesel. Essas medidas trouxeram alguns desafios ao longo do processo de queima do diesel para a geração de energia elétrica.

O biodiesel é obtido mediante óleos vegetais apresentando algumas peculiaridades que devem ser levadas em consideração para o correto entendimento dos desafios impostos pela sua utilização juntamente ao diesel (Uriarte, 2010). A característica de higroscopicidade aliada à sua constituição molecular propicia o aparecimento de bactérias e fungos (Atadashi, Aroua, \& Abdul Aziz, 2010). Tais organismos causam a deterioração do combustível, dos metais dos tanques, tubulações e equipamentos, como os geradores. Os produtos dessa degradação se acumulam no processo causando obstrução de bicos injetores de combustível, além de se acumularem nos equipamentos na forma de depósitos, causando em última instância, custosas paradas de manutenção. $\mathrm{O}$ acúmulo acelerado de tais materiais nos filtros do sistema também causam 
maiores paradas de manutenção, causando gastos em peças de reposição bem como prejuízos por causa da descontinuidade de fornecimento de energia elétrica para o mercado (Lapuerta, Armas, \& Rodríguez-fernández, 2008).

Tais desafios vêm sendo superados de forma exitosa na UTE Santana, pela Eletronorte em parceria com a BR distribuidora bem como a fornecedora do aditivo, a Actioil.

\section{HISTÓRICO}

O sistema de Energia do Amapá iniciou suas operações em 1957, caracterizando-se como um sistema hidrotérmico isolado do Sistema Integrado Nacional. O sistema de geração de energia elétrica é composto basicamente da Usina Hidrelétrica de Coaracy Nunes (UHE Coaracy Nunes) e da Usina Termoelétrica de Santana (UTE Santana) além de outras usinas termoelétricas de menor porte espalhadas por todo o estado.

A economia do estado é baseada principalmente no setor terciário, com grande movimentação de mercadorias no porto de Santana. As indústrias respondem por uma pequena parcela e estão basicamente fundamentadas na extração mineral, principalmente minério de ferro, serrarias e fábricas de tijolos. Embora o estado tenha uma demanda relativamente baixa por energia elétrica, vinha encontrando problemas e insuficiência em sua geração.

Para aumentar o fornecimento de energética do estado a UTE de Santana entrou em operação em 1993 com a capacidade de geração de 116,4 MW. Atualmente o sistema é composto por três turbinas geradoras do tipo LM2500, quatro motores Wartsila e 32 grupos geradores Caterpillar. O consumo de óleo diesel dos geradores é de 600 a $1000 \mathrm{~m}^{3} /$ dia, com um teor de enxofre de 1800 ppm e 5\% de biodiesel. Assim, a mistura de diesel com biodiesel, tem um papel crucial na matriz energética do estado do Amapá.

\section{OS DESAFIOS ENFRENTADOS}

A utilização do diesel com biodiesel, pela UTE Santana, resultou no aparecimento de grande quantidade de depósitos, conhecidos como borra, nos tanques, filtros e geradores, tal como o colocado nas Figura 1. 


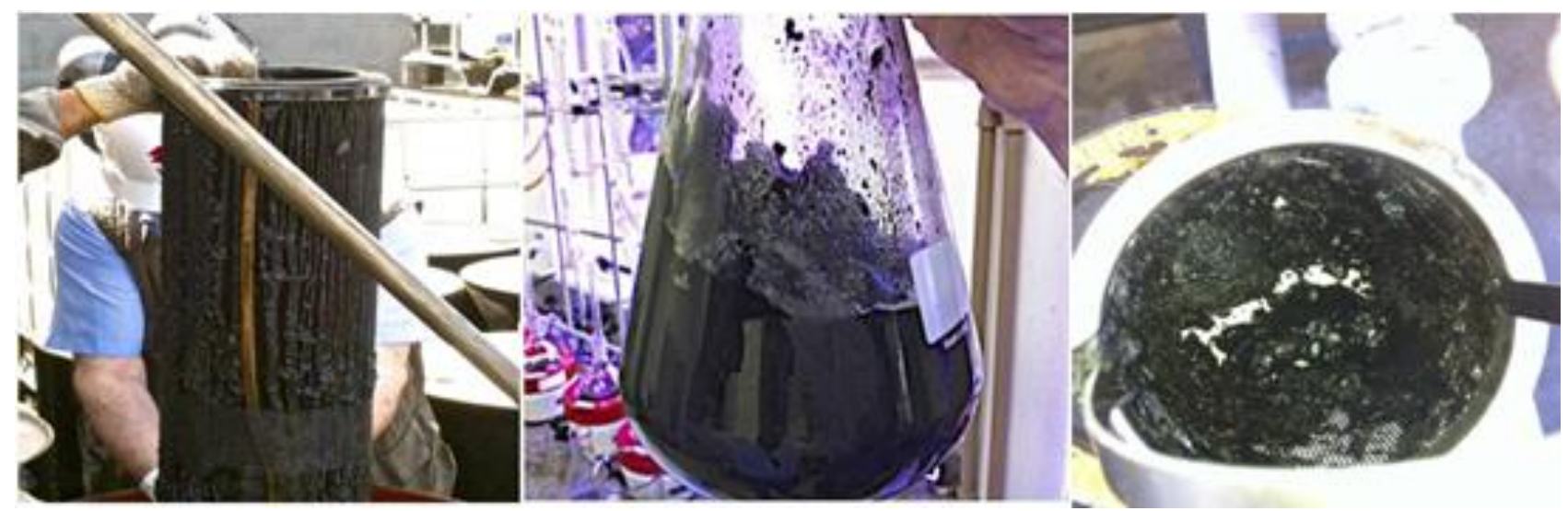

Figura 1. Filtro cesta contendo grande quantidade de borra. Condição encontrada anteriormente à utilização do diesel aditivado.

Observou-se também a perda de produtividade na geração e no fornecimento de energia elétrica, causando instabilidades e inseguranças com relação ao funcionamento da UTE. Além disso, também foram observadas mudanças nas composições dos gases de combustão com relação à quantidade de elementos poluidores.

\section{OBJETIVOS}

Utilizou-se de metodologias para verificar a eficiência do uso de diesel aditivado com Actioil A550 na UTE Santana. Tal ação se deu mediante quatro frentes de pesquisa: 1. Tratamento laboratorial do diesel deteriorado, amostrado dos tanques de armazenamento, com o A500; 2. Ensaios de corrosão em laboratório; 3. Aferições mensais da composição dos gases de combustão do diesel; 4. Inspeções visuais dos equipamentos e tubulações nas paradas da UTE Santana para manutenção.

\section{MATERIAIS E MÉTODOS}

A amostragem de diesel foi realizada do fundo dos tanques de estocagem. O tratamento do diesel em laboratório foi realizado mediante aditivação com A550, filtragens e lavagem com água, seguido de sedimentação da amostras.

Os ensaios de corrosão foram feitos em placas de aço carbono, mesmo material da tancagem de diesel. Utilizou-se diferentes dosagens de A550 e observou-se visualmente ao longo dos dias os efeitos da superficiais da corrosão na placa.

As medidas de $\mathrm{CO}, \mathrm{O}_{3}$ e $\mathrm{NO}_{\mathrm{x}}$ foram realizadas com analisador de gases modelo TESTO $350 \mathrm{XL}$ (Figura 2), de leitura contínua e princípio de medição por célula eletroquímica. Este sistema obtém análise instantânea das condições de emissão e do rendimento energético do combustível sendo queimado. O processo de análise continuada, se comparado com os processos de análise 
pontual, permitem maior correlação entre os dados de processo (vazão de diesel, concentração em aditivos e água), com as emissões gasosas.

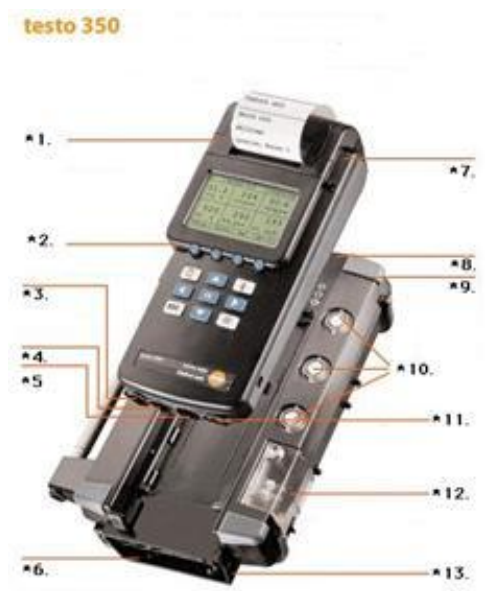

Figura 2. Equipamento utilizado para monitorar gases $\mathrm{O2}, \mathrm{CO}$ e $\mathrm{NO}$ e seus derivados.

As inspeções visuais dos equipamentos foram realizadas em visitas à UTE Santana durante as paradas para manutenção. A aditivação do diesel fornecido para UTE Santana no período de avaliação foi realizada mediante a adição de A550 nos caminhões tanque a uma concentração de 1000 ppmv (1 L de A550 para 1000 L de diesel).

\section{RESULTADOS}

Os resultados obtidos ao longo do período de utilização do diesel aditivado com A550 são colocados ao longo dos itens que se seguem.

\subsection{Tratamento do diesel em laboratório:}

O diesel coletado nos tanques foi submetido a tratamento em laboratório. As principais operações realizadas foram a aditivação, filtração, decantação e lavagem com água. As técnicas simples de tratamento possibilitam que sejam aplicadas a níveis industriais sem necessidade de grandes investimentos. As Figuras 3, 4, 5 e 6 trazem os resultados obtidos no tratamento laboratorial do diesel amostrado. 

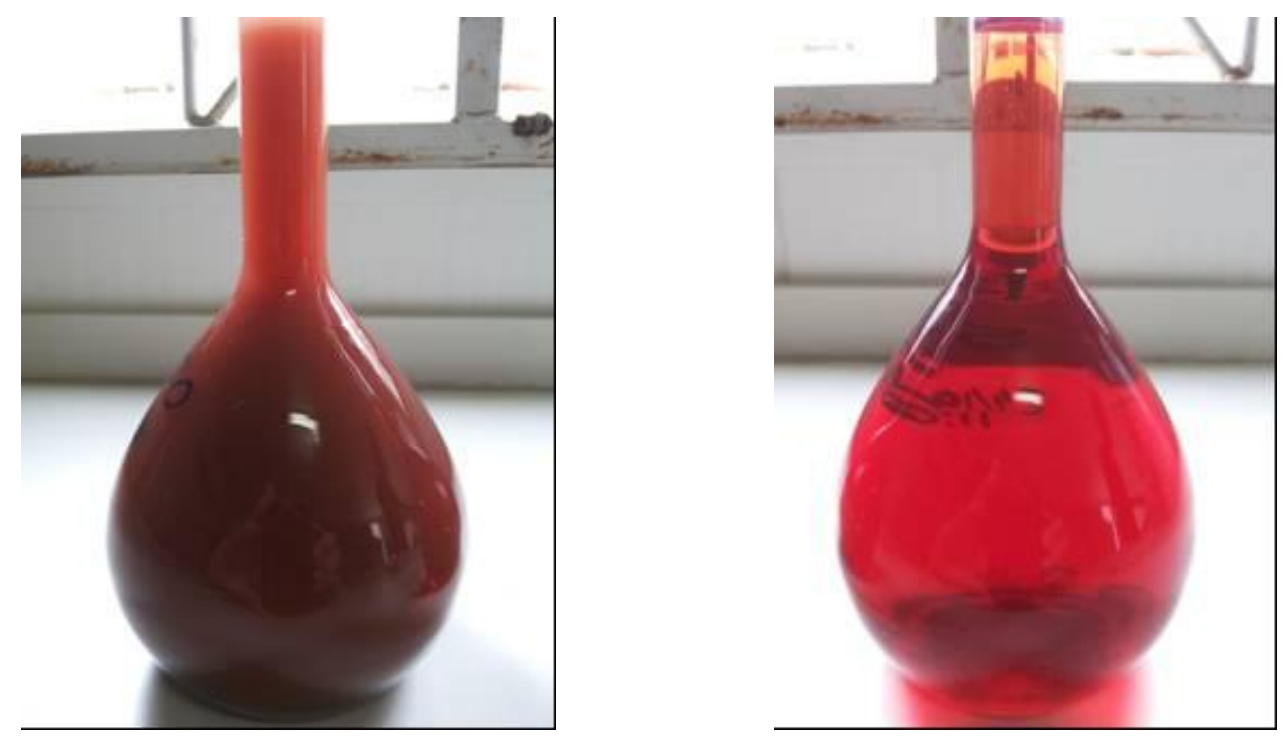

Figura 3. Diesel BS 500 recolhido de fundo de tanque para tratamento. Amostra sem aditivo e amostra 15 dias após a coleta, tratada com A550 - Actioil.
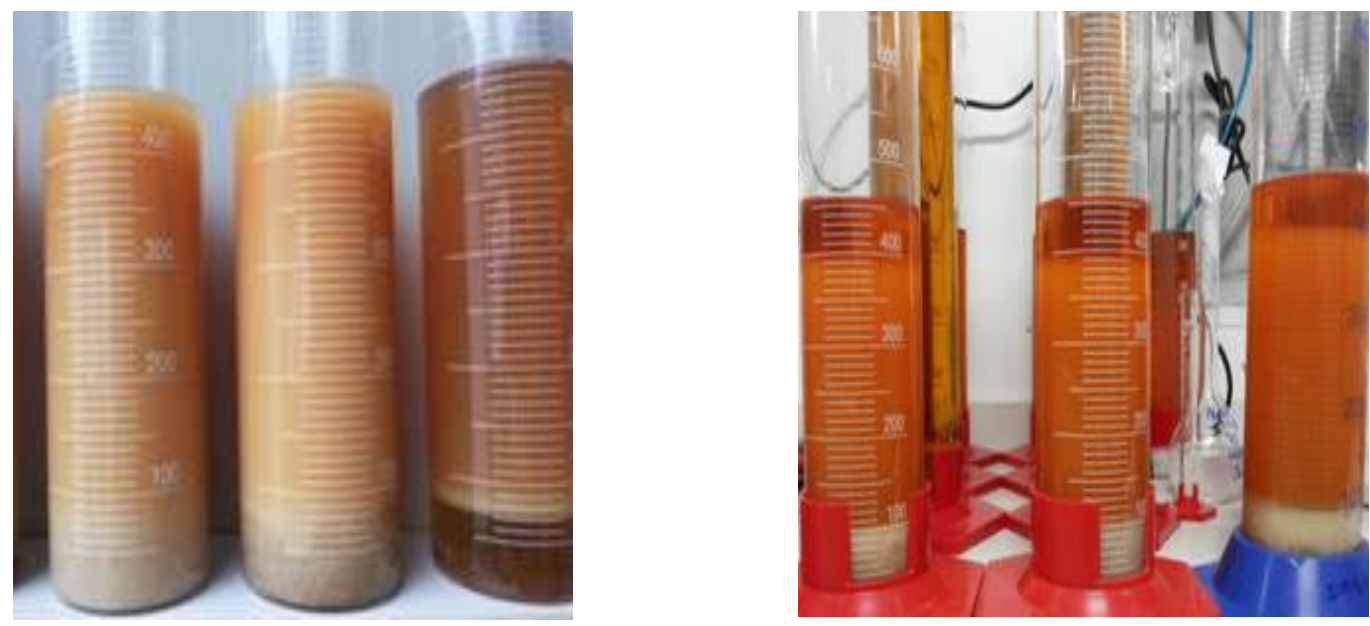

Figura 4. Diesel BS 1800 recolhido de fundo de tanque para tratamento. Amostras coletadas em Abril de 2011, sendo tratadas em laboratório e armazenadas até a data de hoje com o aspecto da foto do lado direito, tratadas com A550 Actioil a 5000 ppm.

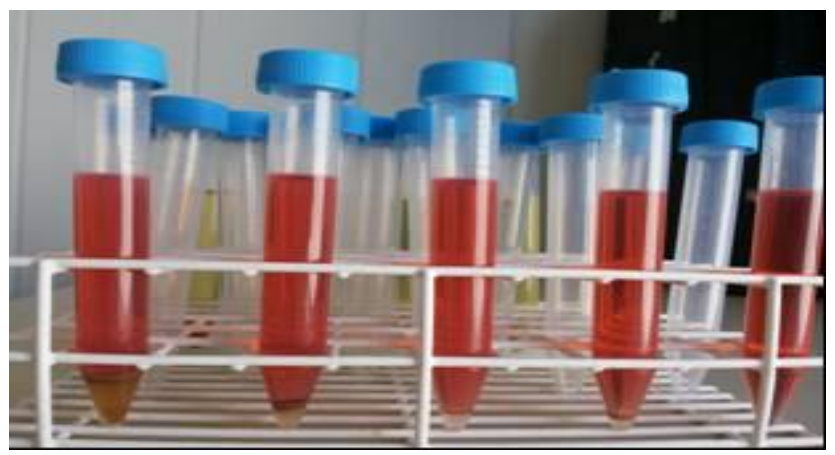

Figura 5. Diesel BS 500 recolhido de fundo de tanque para tratamento. Amostras tratadas com o aditivo e após sedimentação, diesel limpo e isento de impurezas (da esquerda para a direita). 


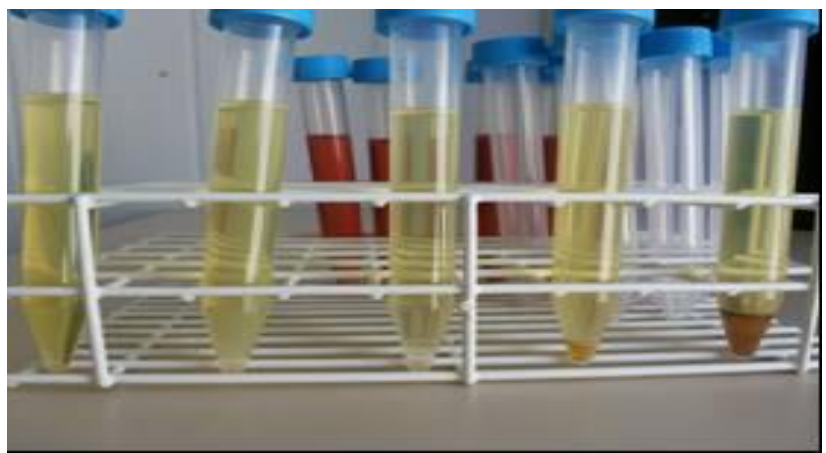

Figura 6. Diesel BS 10 recolhido de fundo de tanque para tratamento. Amostras tratadas com o aditivo e após sedimentação, Diesel limpo e isento de impurezas.

\subsection{Ensaio de corrosão:}

O ensaio de corrosão, realizado com a aditivação do diesel a 1000, 3000 e 5000 ppm de A550 podem ser observados na Figura 7. Os ensaios foram realizados em placa de Petri com uma duração de $240 \mathrm{~h}$ cada experimento. Todos os ensaios foram realizados em triplicata.
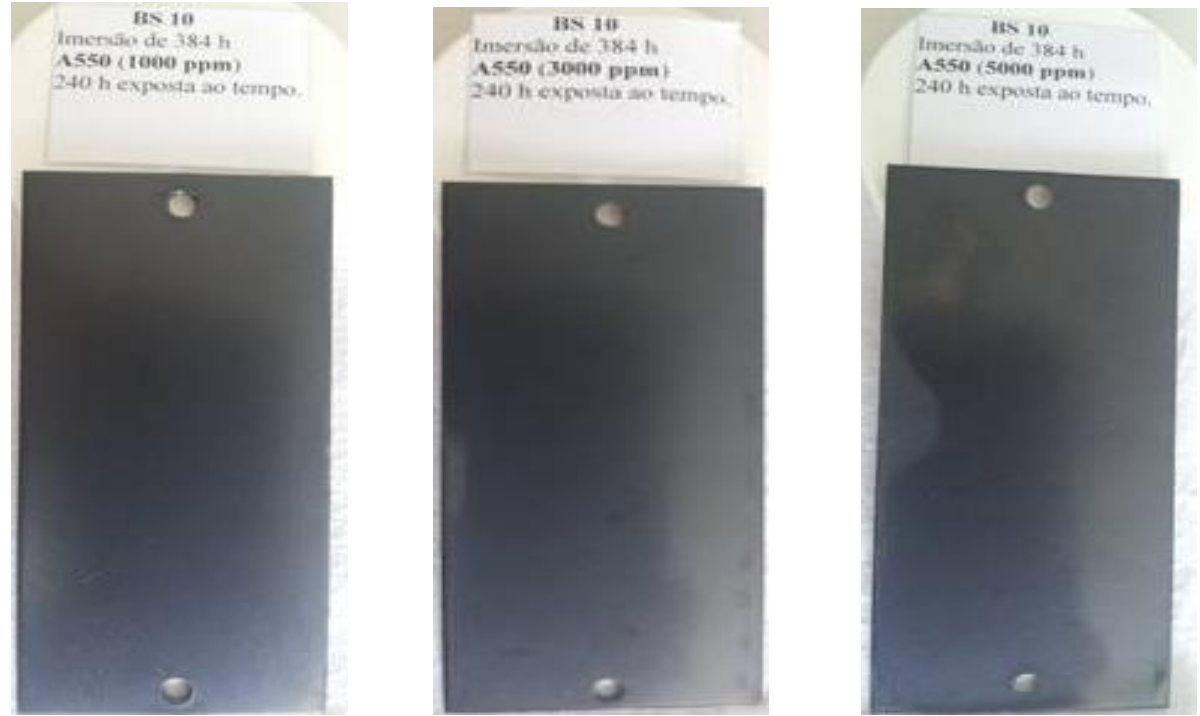

Figura 7. Amostras de aço carbono, mesmo material que são feitos os tanques de armazenamento do diesel imersas em diesel BS 10 com 0,1\%, 0,3 e 0,5\% respectivamente de Aditivo A550-Actioil. Amostras sem sinais de oxidação.

\subsection{Monitoramento da qualidade dos gases de combustão:}

O monitoramento da qualidade dos gases de combustão foi realizado antes do uso do diesel aditivado com A550, pela UTE Santana e posteriormente à utilização do A550 pelos Institutos Lactec.

Nas tabelas I, II observa-se para uma geração de 15,70 MW (média horária), as diferenças dos poluentes gerados em decorrência de um ajuste de potência. Os dados apresentados mostram uma questão importante para a avaliação do processo de queima e no controle de emissão que podem ser comparados com limites em legislação estadual e/ou federal e ainda apontar problemas na redução da potência nominal de uma máquina. 
Tabela I. Monitoramento das emissões em função da potência medida - Julho de 2011.

\begin{tabular}{|c|c|c|c|c|c|c|c|c|c|}
\hline \multicolumn{10}{|c|}{ Julho de 2011} \\
\hline & 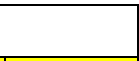 & \multicolumn{2}{|c|}{ Máquina 04} & \multicolumn{2}{|l|}{ Máquina 05} & \multicolumn{2}{|c|}{ Máquina 06} & \multicolumn{2}{|c|}{ Máquina 07} \\
\hline $\mathrm{O} 2 \mathrm{ref}$ & 3 & BCM A & BCM B & BCM A & BCM B & BCM A & BCM B & BCM A & BCM B \\
\hline $\mathrm{O} 2$ & $\%$ & 13,60 & 13,30 & 13,40 & 13,20 & 12,60 & 12,60 & 13,50 & 13,20 \\
\hline $\mathrm{CO}$ & $\mathrm{mg} / \mathrm{m}^{3}$ & 83,71 & 97,90 & 123,30 & 105,00 & 103,73 & 100,33 & 111,27 & 139,25 \\
\hline $\mathrm{CO} 2$ & $\%$ & 258064,36 & 257195,45 & 255926,40 & 253898,08 & 256812,72 & 252602,68 & 254623,50 & 258431,97 \\
\hline $\mathrm{SO} 2$ & $\mathrm{mg} / \mathrm{m}^{3}$ & 543,16 & \begin{tabular}{|l|}
378,70 \\
\end{tabular} & 347,45 & \begin{tabular}{|l|l}
461,54 \\
\end{tabular} & 499,93 & 512,14 & 454,32 & 586,15 \\
\hline NO & $\mathrm{mg} / \mathrm{m}^{3}$ & 3395,68 & 3511,17 & 3602,37 & 3170,77 & 3072,86 & 3083,57 & 2812,80 & 2778,46 \\
\hline $\mathrm{NO} 2$ & $\mathrm{mg} / \mathrm{m}^{3}$ & 1958,11 & 2026,75 & 2081,84 & 1830,00 & 1774,29 & 1778,57 & 1620,00 & 1603,85 \\
\hline NOx & $\mathrm{mg} / \mathrm{m}^{3}$ & 5353,78 & 5537,92 & 5684,21 & 5000,77 & 4847,14 & 4862,14 & 4432,80 & 4382,31 \\
\hline $\begin{array}{l}\text { Pot. } \\
\text { Nom. }\end{array}$ & MW & 15,70 & 15,70 & 15,70 & 15,70 & 15,70 & 15,70 & 15,70 & 15,70 \\
\hline $\begin{array}{l}\text { Pot. } \\
\text { Medida }\end{array}$ & MW & 13,93 & 13,93 & 13,73 & 13,73 & 13,85 & 13,85 & 13,24 & 13,24 \\
\hline
\end{tabular}

Tabela II. Monitoramento das emissões em função da potência medida - Dezembro de 2011.

\begin{tabular}{|c|c|c|c|c|c|c|c|c|c|}
\hline \multicolumn{10}{|c|}{ Dezembro de 2011} \\
\hline \multirow{3}{*}{$\begin{array}{l}\text { Dezem } \\
\mathrm{O} 2 \mathrm{ref} \\
\mathrm{O} 2\end{array}$} & \multirow{2}{*}{3} & \multicolumn{2}{|c|}{ Máquina 04} & \multicolumn{2}{|c|}{ Máquina 05} & \multicolumn{2}{|c|}{ Máquina 06} & \multicolumn{2}{|c|}{ Máquina 07} \\
\hline & & BCM A & BCM B & BCM A & BCM B & BCM A & BCM B & BCM A & BCM B \\
\hline & $\%$ & 13,80 & 13,20 & 13,70 & 13,50 & 11,90 & 11,80 & 13,50 & 13,10 \\
\hline $\mathrm{CO}$ & $\begin{array}{l}\mathrm{mg} / \\
\mathrm{m}^{3}\end{array}$ & 137,50 & 113,08 & 122,55 & 122,40 & 367,91 & 307,17 & 143,28 & 141,27 \\
\hline $\mathrm{CO} 2$ & $\%$ & $\begin{array}{l}255409, \\
38 \\
\end{array}$ & \begin{tabular}{|l}
279967, \\
97 \\
\end{tabular} & \begin{tabular}{|l}
260321, \\
09 \\
\end{tabular} & $\begin{array}{l}265232, \\
81\end{array}$ & $\begin{array}{l}324173, \\
44 \\
\end{array}$ & \begin{tabular}{|l}
329085, \\
16 \\
\end{tabular} & \begin{tabular}{|l}
265232, \\
81 \\
\end{tabular} & $\begin{array}{l}279967, \\
97 \\
\end{array}$ \\
\hline $\mathrm{SO} 2$ & $\begin{array}{l}\mathrm{mg} / \\
\mathrm{m}^{3}\end{array}$ & 0,00 & 0,00 & 0,00 & 66,75 & 149,25 & 145,00 & 77,50 & 129,25 \\
\hline $\mathrm{NO}$ & $\begin{array}{l}\mathrm{mg} / \\
\mathrm{m}^{3}\end{array}$ & 2585,00 & 2732,50 & 2922,50 & 2747,50 & 2855,00 & 2940,00 & 2367,50 & 2472,50 \\
\hline $\mathrm{NO} 2$ & $\begin{array}{l}\mathrm{mg} / \\
\mathrm{m}^{3}\end{array}$ & 80,00 & 85,00 & 90,00 & 85,00 & 87,50 & 90,00 & 75,00 & 75,00 \\
\hline NOx & $\begin{array}{l}\mathrm{mg} / \\
\mathrm{m}^{3}\end{array}$ & 2665,00 & 2817,50 & 3012,50 & 2832,50 & 2942,50 & 3030,00 & 2442,50 & 2547,50 \\
\hline $\begin{array}{l}\text { Pot. } \\
\text { Nom. }\end{array}$ & MW & 15,70 & 15,70 & 15,70 & 15,70 & 15,70 & 15,70 & 15,70 & 15,70 \\
\hline $\begin{array}{l}\text { Pot. } \\
\text { Medi } \\
\text { da }\end{array}$ & MW & 13,43 & 13,43 & 13,85 & 13,85 & 12,59 & 12,59 & 13,28 & 13,28 \\
\hline
\end{tabular}


A Tabela III traz os resultados obtidos com os gases de combustão da UTSA-SAUGG02.

Tabela III. Resultados de medições de gases de combustão - UTSA-SAUGG02.

\begin{tabular}{|c|c|c|c|c|c|c|c|c|c|c|}
\hline \multirow{2}{*}{$\begin{array}{l}\text { Proces } \\
\text { so } \\
\text { Monit } \\
\text { orado }\end{array}$} & & \multicolumn{2}{|c|}{\begin{tabular}{|l|} 
Parâmetros \\
de Processo \\
Combustão \\
Controle \\
\end{tabular}} & \multicolumn{4}{|c|}{$\begin{array}{l}\text { Parâmetros Monitorados } \\
\text { Média } 10 \text { minutos Corrigidos para } \\
\text { condição referencial de oxigênio. }\end{array}$} & \multicolumn{3}{|c|}{$\begin{array}{l}\text { Parâmetros } \\
\text { UTESantana }\end{array}$} \\
\hline & \multirow[t]{2}{*}{ Data } & $\mathbf{O}_{2 \text { ref }}$ & $\mathbf{O}_{2}$ & $\mathrm{CO}$ & $\mathrm{NO}_{\mathrm{x}}$ & $\mathrm{SO}_{2}$ & $\mathrm{CO}_{2}$ & $\begin{array}{l}\text { Poten } \\
\text { cia }\end{array}$ & Temp & eraturas \\
\hline & & {$[\%]$} & $\begin{array}{l}{[\%} \\
]\end{array}$ & [\%] & $\begin{array}{l}{[\mathrm{mg} / \mathbf{N}} \\
\left.\mathbf{m}^{3}\right]\end{array}$ & {$\left[\mathrm{mg} / \mathrm{Nm}^{3}\right]$} & {$\left[\mathrm{mg} / \mathrm{Nm}^{3}\right]$} & $\begin{array}{l}{[\mathrm{MW}} \\
\text { atts }]\end{array}$ & $\begin{array}{l}\text { Proc } \\
\text { esso } \\
{\left[{ }^{\circ} \mathrm{C}\right]}\end{array}$ & $\begin{array}{l}\text { Ambie } \\
\text { nte } \\
{\left[{ }^{\circ} \mathrm{C}\right]}\end{array}$ \\
\hline $\begin{array}{l}\text { SAUG } \\
\text { G02 }\end{array}$ & $\begin{array}{l}24 / 04 \\
/ 2012 \\
\end{array}$ & 3,00 & $\begin{array}{l}16, \\
69\end{array}$ & 88,59 & $\begin{array}{l}1004,2 \\
5\end{array}$ & 74,67 & 240647,84 & 13,37 & $\begin{array}{l}1404, \\
00\end{array}$ & 31,97 \\
\hline $\begin{array}{l}\text { SAUG } \\
\text { G02 }\end{array}$ & $\begin{array}{l}24 / 04 \\
/ 2012\end{array}$ & 3,00 & $\begin{array}{l}15, \\
04\end{array}$ & 37,83 & 814,27 & 83,90 & 173097,71 & 15,11 & $\begin{array}{l}1486, \\
30\end{array}$ & 35,84 \\
\hline $\begin{array}{l}\text { SAUG } \\
\text { G02 }\end{array}$ & $\begin{array}{l}19 / 06 \\
/ 2012\end{array}$ & 3,00 & $\begin{array}{l}17, \\
01\end{array}$ & 71,96 & $\begin{array}{l}1131,4 \\
7\end{array}$ & 20,92 & 242572,91 & 13,24 & $\begin{array}{l}1509, \\
00\end{array}$ & 37,70 \\
\hline
\end{tabular}

A Tabela IV traz os resultados obtidos com os gases de combustão da UTSA-SAUGG05-B.

Tabela IV - Resultados de medições de gases de combustão - UTSA-SAUGG05-B.

\begin{tabular}{|c|c|c|c|c|c|c|c|c|c|c|}
\hline \multirow{2}{*}{$\begin{array}{l}\text { Processo } \\
\text { Monitorad } \\
\text { o }\end{array}$} & \multirow[b]{2}{*}{ Data } & \multicolumn{2}{|c|}{$\begin{array}{l}\text { Parâmetros de } \\
\text { Processo } \\
\text { Combustão } \\
\text { Controle }\end{array}$} & \multicolumn{4}{|c|}{$\begin{array}{l}\text { Parâmetros Monitorados } \\
\text { Média } 10 \text { minutos Corrigidos } \\
\text { para condição referencial de } \\
\text { oxigênio. }\end{array}$} & \multicolumn{3}{|c|}{$\begin{array}{l}\text { Parâmetros } \\
\text { UTESantana }\end{array}$} \\
\hline & & $\mathbf{O}_{2 \text { ref }}$ & $\mathrm{O}_{2}$ & $\mathrm{CO}$ & $\mathrm{NO}_{\mathrm{x}}$ & $\mathrm{SO}_{2}$ & $\mathrm{CO}_{2}$ & $\begin{array}{l}\text { Potenc } \\
\text { ia }\end{array}$ & Tempe & aturas \\
\hline \multirow{5}{*}{$\begin{array}{l}\text { SAUGD05 } \\
\text { B } \\
\text { SAUGD05 } \\
\text { B } \\
\text { SAUGD05 } \\
\text { B } \\
\text { SAUGD05 } \\
\text { B }\end{array}$} & & {$[\%]$} & [\%] & $\begin{array}{l}{[\mathrm{mg} / \mathrm{N}} \\
\left.\mathrm{m}^{3}\right]\end{array}$ & $\begin{array}{l}{[\mathrm{mg} / \mathrm{N}} \\
\left.\mathbf{m}^{3}\right]\end{array}$ & $\begin{array}{l}{[\mathrm{mg} / \mathrm{Nm}} \\
\left.{ }_{3}\right]\end{array}$ & $\begin{array}{l}{[\mathrm{mg} / \mathrm{Nm}} \\
\text { 3] }\end{array}$ & $\begin{array}{l}{[\mathbf{M W a}} \\
\text { tts }]\end{array}$ & $\begin{array}{l}\text { Proces } \\
\text { so } \\
{\left[{ }^{\circ} \mathrm{C}\right]}\end{array}$ & $\begin{array}{l}\text { Ambien } \\
\text { te } \\
{\left[{ }^{\circ} \mathrm{C}\right]}\end{array}$ \\
\hline & $\begin{array}{l}23 / 04 / 20 \\
12\end{array}$ & 3,00 & 14,31 & 88,50 & $\begin{array}{l}5269,8 \\
6 \\
\end{array}$ & 113,90 & $\begin{array}{l}245601, \\
14\end{array}$ & 10,13 & 351,10 & 36,56 \\
\hline & $\begin{array}{l}18 / 06 / 20 \\
12\end{array}$ & 3,00 & 13,15 & 177,10 & $\begin{array}{l}5292,4 \\
6 \\
\end{array}$ & 38,87 & $\begin{array}{l}251500, \\
22\end{array}$ & 8,59 & 380,34 & 37,58 \\
\hline & $\begin{array}{l}17 / 07 / 20 \\
12\end{array}$ & 3,00 & 13,60 & 93,40 & $\begin{array}{l}5585,8 \\
7\end{array}$ & 0,70 & $\begin{array}{l}253949 \\
68\end{array}$ & 10,13 & 336,56 & 31,23 \\
\hline & $\begin{array}{l}27 / 08 / 20 \\
12\end{array}$ & 3,00 & 13,31 & 108,88 & $\begin{array}{l}5187,0 \\
8\end{array}$ & 20,09 & $\begin{array}{l}258949, \\
68\end{array}$ & 12,50 & 357,50 & 39,00 \\
\hline
\end{tabular}


Para as tabelas I e II, dados geradas após monitoramento realizado pela própria UTE de Santana, para máquinas com potência nominal de 15,7 MW. As máquinas que apresentam problemas com formação de borras devido à oxidação acelerada do diesel, as emissões acusam altos valores para o poluente NOx, quando a potência nominal da máquina não é atendida.

Porém, na tabela III, após tratamento do diesel e dos motores com o aditivo A550 da Actioil, na proporção de $0,1 \%$ ou 1000 ppm, mesmo para potências abaixo da nominal, os valores de NOx são reduzidos drasticamente.

$\mathrm{Na}$ tabela IV, as potências são reduzidas ainda mais, havendo um descontrole de processo fazendo com que o poluente NOx seja aumentado e retorne a ser emitido descontroladamente. Porém, o poluente $\mathrm{CO}$ ainda encontra-se com valores baixos.

Cabe salientar que existe um limite para redução de potência e que, levando-se em conta a aditivação, tem-se excelentes resultados para uma queda de potência de até $15 \%$ abaixo da potência nominal. O que pode ser afirmado é que para a geração de energia, quando as máquinas estão trabalhando com redução de potencia em até $10 \%$ da sua capacidade nominal, os poluentes $\mathrm{NO}_{\mathrm{x}}$ e CO são reduzidos drasticamente desde que o diesel utilizado, esteja tratado com $0,1 \%$ ou 1000 ppm de Aditivo A550 para cada litro de diesel.

Observa-se também um ganho em eficiência e redução do consumo de diesel ao se comparar horas trabalhadas com a energia gerada e o combustível utilizado.

\subsection{Inspeções visuais na UTE Santana}

As Figuras 8, 9 e 10 trazem os resultados das inspeções dos filtros e da tomada de diesel nos tanques de armazenamento.
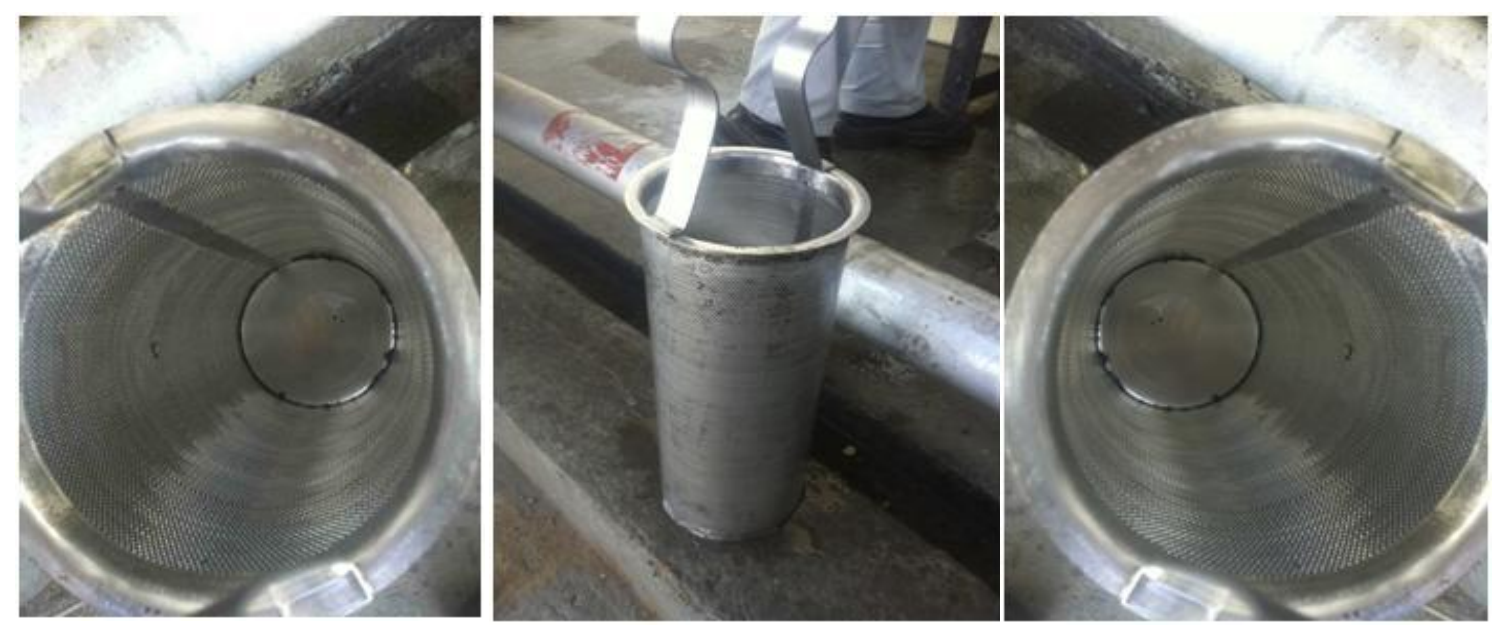

Figura 8. Vista do filtro cesta da centrífuga após noventa dias de utilização do diesel aditivado com A550 da Actioil. 


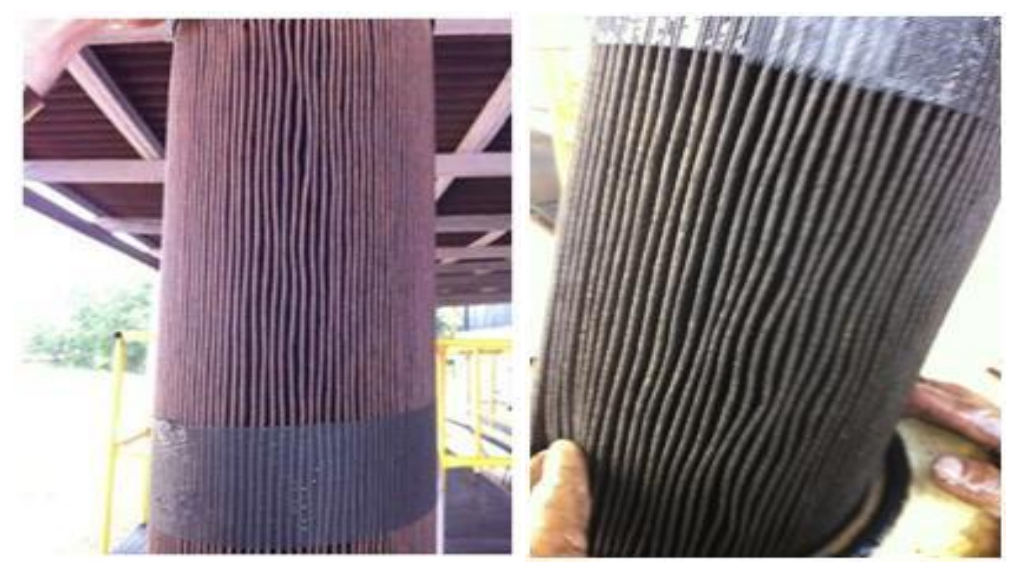

Figura 9. Vista dos filtros após injeção do aditivo A550 da Actioil.
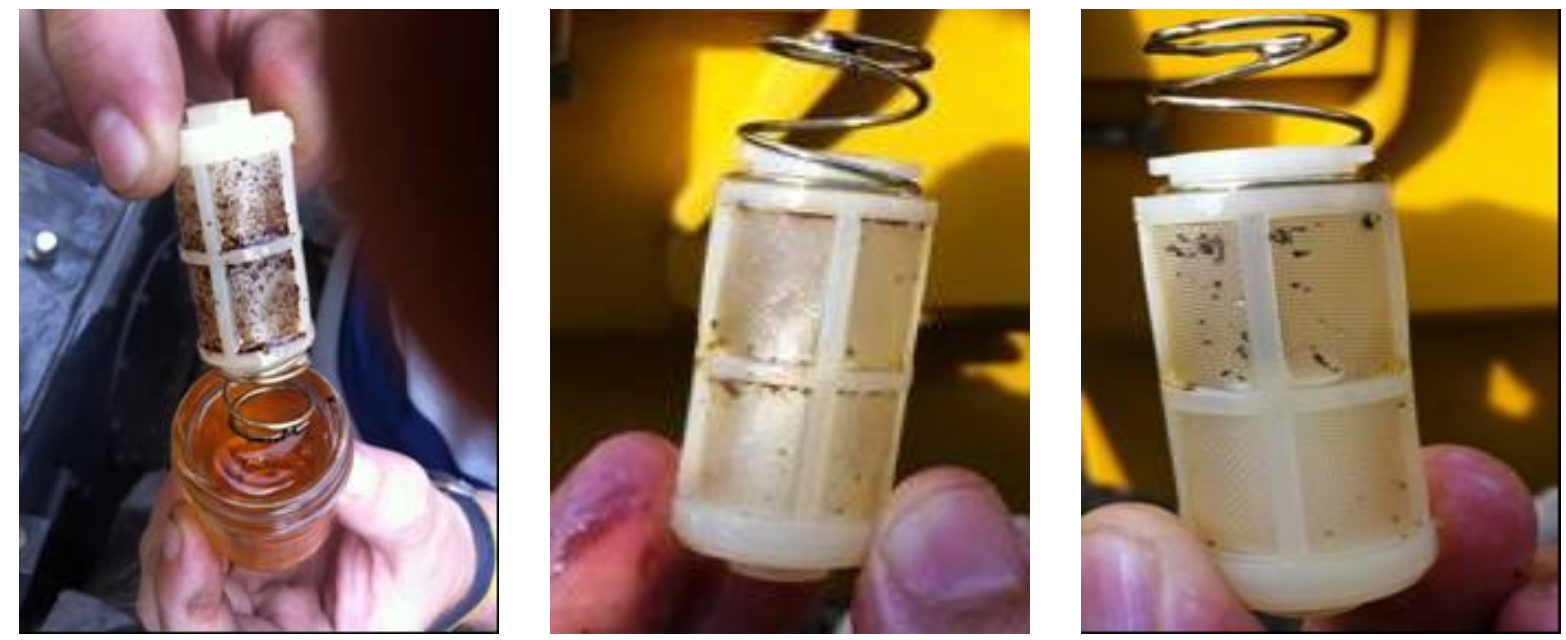

Figura 10. Vista da tomada de combustível diesel (pescador) antes da aditivação e depois da aditivação com A550 da Actioil, 30 e 45 dias.

\section{DISCUSS ÃO E CONCLUSÕES}

Observou-se mediante as quatro estratégias de monitoramento da eficiência da utilização do diesel aditivado com A550 uma melhora significativa em todos os processos por onde o diesel passa, na UTE Santana, até sua queima e exaustão de gases. Quando se trata da exaustão de gases é de suma importância ressaltar o controle de emissões de $\mathrm{NO}_{\mathrm{x}}$ e $\mathrm{CO}$ quando os geradores são operados abaixo de sua potência nominal, quando se há a utilização do diesel aditivado com A550 Actioil.

Os ensaios laboratoriais mostraram que com operações físicas simples pode-se devolver as qualidades do diesel, evitando que grandes lotes sejam perdidos, ou até mesmo que partes significativas do diesel presente em tanques seja drenada e descartada. É notório o tempo que o 
diesel aditivado pode ser estocado em laboratório em condições igualáveis às do diesel fornecido pela BR Distribuidora.

Com relação aos ensaios de corrosão pode-se observar uma proteção do metal mesmo em concentrações relativamente baixas de aditivo.

As paradas para manutenção da planta evidenciaram que com o uso do diesel aditivado há quase completa extinção da borra formada. Com isso, os prejuízos com paradas para troca de peças, perda de pressão nos bicos injetores com consequente perda de eficiência nos motores, pôde ser resolvido.

O atual trabalho também identificou que há a necessidade em criar um banco de dados com estas informações é de fundamental necessidade para o controle seja a caráter operacional do processo com regulagens ou até mesmo, dos gases emitidos pela queima do combustível considerado, seja ele fóssil ou não.

\section{REFERÊNCIAS BIBLIOGRÁFICAS}

(s.d.). Acesso em 10 de maio de 2014, disponível em ANEEL: www.aneel.gov.br

Atadashi, I. M., Aroua, M. K., \& Abdul Aziz, A. (2010). High quality biodiesel and its engine application: A review. Renewable and Sustainable Energy Reviews (14), 1999-2008.

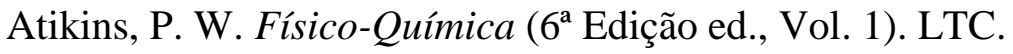

Chigier, N. (1986). Energy, Combustion and Environment. Estados Unidos da América: McGrallHill.

Fahim, M. A., Al-Sahhaf, T. A., \& Elkilani, A. S. (2010). Fundamentals of Petroleum Refining. Amsterdãm: Eslevier.

Lapuerta, M., Armas, O., \& Rodríguez-fernández, J. (2008). Effect of biodiesel fuels on diesel engine emissions. Progress in Energy and Combustin Science (34), 198-223.

Lewtas, J. (2007). Air pollution combustion emissions: Characterization of causative agents and mechanisms associated with cancer, reproductive, and cardiovascular effects. Mutation Research (636), 95-133.

Nidal, H., \& Abu-Hamadeh, N. H. (2003). Effect of cooling the recirculated exhaust gases on diesel engine emissions. ENERGY. Conversion \& Management (44), 3113-3124.

Speight, J. G. (2006). The Chemistry and Technology of Petroleum. CRC Press.

Uriarte, F. A. (2010). Biofuels from Plant Oils. Jakarta: ANSEAN Foundation. 


\section{SOBRE OS AUTORES}

Jair Duarte, nascido em Curitiba, PR em 28 de Julho de 1974. Mestrando na área de Desenvolvimento de Tecnologia (previsto 2009) - PRODETEC - IEP - LACTEC, Especialização em Gerenciamento Ambiental na Industria pela FIEP e UFPR (2003) e Graduado pela UFPR (2002) em Engenharia Química.

Empresa: Instituto de Tecnologia para o Desenvolvimento - LACTEC desde 2002, atuando como pesquisador na área de meio ambiente;

Ezequiel Orlandi, nascido em Ribeirão Preto, SP em 12 de Setembro de 1986, é graduado pela UFPR (2014) em Engenharia Química.

Empresa: Instituto de Tecnologia para o Desenvolvimento - LACTEC desde 2013, atuando como pesquisador na área de meio ambiente. 